\title{
Compensation Incentives and Risk Taking Behavior: Evidence from Mutual Funds
}

\author{
Athanasios Orphanides* \\ Board of Governors of the Federal Reserve System
}

May 1996

\begin{abstract}
This paper examines the role of compensation contracts in determining risk taking decisions by money managers in the financial industry. A methodology is developed for empirically testing and assessing the magnitude of the effect that incentive contracts have on risk taking in the mutual fund industry using panel data. The methodology exploits the withinyear cross sectional variation in the performance of mutual funds to identify systematic time series variation in risk taking. Growth and growth and income mutual funds in the 1976 to 1993 period are examined. The evidence suggests that incentive compensation has substantial influence on risk decisions. A strong seasonal component on average risk is present with risk reaching a peak in the first quarter of the year. However the relationship between within-year performance, especially towards year-end, appears to have changed over time. For losing managers, excess risk taking appears early in the sample but not in later years. For winning managers, reductions in risk taking appears towards year-end in later years but not early in the sample.

KEYWORDS: Risk taking, compensation incentives, mutual fund performance.

JEL Classification System: D81, G11, J33

Correspondence: Athanasios Orphanides, Division of Monetary Affairs, Board of Governors of the Federal Reserve System, Washington, D.C. 20551. Tel.: (202) 452-2654, email: aorphanides@frb.gov *This is a revised draft of a paper prepared for the Joint Central Bank Research Conference on Risk Measurement and Systemic Risk, Federal Reserve Board, Washington, DC, November 16-17, 1995. I would like to thank conference participants and participants at workshops at the Johns Hopkins University, the University of Kansas and the Federal Reserve Bank of Kansas City for comments and discussions. Jim Walsh provided valuable research assistance. The opinions expressed are those of the author and do not necessarily reflect the views of the Board of Governors of the Federal Reserve System.
\end{abstract}




\section{Introduction}

Traders and money managers are paid to play with other people's money. Their job is to take risks and maximize returns within some broad guidelines regarding trading/investment objectives and risk tolerance. And, for acting as their customers' agents, they are compensated with incentive contracts that reward superior results and weed out underperformers.

Whether current practices in compensation contracts lead to efficient outcomes, however, is an open question. Recent advances in agency theory have established theoretical foundations for understanding how compensation contracts can influence an agent's decisions in many settings, including money management. The theoretical results suggest that agents' decisions regarding effort, choice among projects with different risk/reward characteristics, and other management issues can be drastically affected by the nature of the incentives. The theory also provides some guidance on the form of optimal compensation schemes under specific assumptions regarding preferences, technology, and contract enforcement. ${ }^{1}$

Of particular interest for trading and money management are the implied links between compensation and risk taking and the suggested possibility that in some instances risk choices may be driven more by the specific nature of incentive contracts and less by the broad guidelines under which a trader or money manager is supposed to operate.

The objective of this paper is to provide a starting point for examining empirically the effect of incentive contracts on risk choices in trading and money management. The primary motivation is to begin addressing the following question: Do the incentive compensation contracts of agents involved in trading affect their behavior with regard to risk taking activities? And if so how?

The question is of interest for several reasons: First, to establish empirically whether the assymetric information and monitoring concerns that permeate the managerial incentives literature are relevant in financial markets. Although anecdotal evidence suggests that

\footnotetext{
${ }^{1}$ See Modigliani and Pogue (1975), Starks (1987), Grinblatt and Titman (1989) and Stoughton (1993) for agency theory applications to risk taking in money management, Hirshleifer and Suh (1992) for the problem of simultaneous effort and risk choice control and Holmstrom and Milgrom (1987) for the key issue of infrequent monitoring and time aggregation.
} 
financial institutions and other entities occasionally experience undesirable losses because of unscrupulous high-risk trading activities by a trader or financial officer, it is not clear how systematic such incidents are. (Of course, even if not systematic, the occasional collapse of a hedge fund, or a loss of $\$ 1$ billion leading to the failure of a major bank, are events worth examining because of their possible repercussions for capital market stability.) Second, to assess the magnitude of the risk taking that might arise because of the structure of compensation schemes. And third, to begin to evaluate the relative merits of alternative compensation schemes in terms of efficiency considerations.

At a practical level, the issues involved might have been of little relevance in years past, when incentive based compensation was only a small part of take-home pay for traders or money managers. Over the past decade, however, anecdotal evidence suggests that the relative importance of bonuses versus base salaries has increased by several multiples in the industry. Consequently, understanding the behavioral consequences of this shift in compensation practices becomes more important.

Despite the interest in the question, empirical analysis which could potentially provide a direct answer is not presently possible. The reason, simply, is the unavailability of data. Currently, there do not appear to exist publicly available data which could detail either (a) the incentive compensation contracts of the agents in this industry or (b) the actual compensation received.

However, to the extent it is possible to measure the performance of agents within a framework that also permits modeling risk decisions, an indirect examination of the issue appears feasible. This possibility is open for mutual funds. There, performance can be objectively measured with publicly available information, and risk can in principle be estimated based on asset pricing models. As a result, if differences in risk decisions likely due to incentive compensation contracts can be empirically identified, their presence can be tested by examining the cross sectional pattern of the time series variation in risk decisions.

A complicating factor is that in the mutual fund industry a second layer of agency problems is present. That is, in addition to the agency problem in the relationship between 
a mutual fund manager and the company employing her, an agency problem is present in the relationship between the shareholders of the fund and the mutual fund company. In assessing changes in risk taken by a mutual fund manager it is therefore necessary to address both layers of the agency problem simultaneously and try to sort out their implications.

Two major distinguishing characteristics of incentive compensation contracts that appear prevalent in the industry enable us to identify differences in behavior likely due to managerial incentive contracts. The first is that the principal performance evaluation period for a mutual fund manager is typically (though not always) the calendar year. The second, is that the annual compensation is determined in large part by a summary measure of the performance of the fund over the evaluation period.

Since managers can observe and, in principle, change to some extent the riskiness of their portfolios at higher frequency intervals, their optimal risk-taking behavior within the year may be determined, in part, by their cumulative performance up to that time. Simply, by controlling the riskiness of their portfolio managers can influence the conditional probability distribution of their year-end performance. Clearly, their optimal choice at any time within a year need not be independent of their performance earlier in the year, nor of the time remaining to the end of the year. Consequently, if compensation incentives do influence the choice of risk by mutual fund managers, this should lead to a pattern of seasonal variations in risk taking behavior which may also depend on the within-year performance variations. Therefore, by exploiting the within-year cross sectional variation in risk decisions we can indirectly detect the presence of incentive compensation effects. By contrast, if managers do not have the flexibility to alter their risk taking behavior within the year in response to their performance up to that time, or their compensation is designed so as to preclude such behavior, then no seasonal pattern and no performance related cross sectional variation in within-year risk choices ought to be observed. This observation provides the basis for a statistical test of the presence and examination of the size of incentive compensation effects.

This paper investigates the presence of patterns in the relationship between past performance and risk for a sample of growth and growth and income oriented mutual funds. As a 
measure of risk, I examine the deviation of a fund's quarterly return from the median return for funds with the same objective. Using the panel of quarterly returns for the competing funds within each group, I estimate simple functional forms of within-year past performance which explain some of the cross-sectional variation in risk.

Two testable hypotheses regarding the direction of the effect are of particular interest. The first is that managers who have performed well earlier in the year may decide to engage in less risky behavior in order to "lock in" their bonuses. ${ }^{2}$ This type of behavior can also be associated with "profit taking" in bull markets. The second is that managers who have performed badly earlier in the year may decide to increase the riskiness of their portfolio in order to raise the probability of improving their year-end performance. This "bold strategy" effect appears to be a major concern in the design of incentive compensation schemes and risk control mechanisms in trading houses and investment banks. ${ }^{3}$ Continuous vigilance by mutual fund companies with the threat of layoff for managers who attempt such a strategy, however, could be sufficient to eliminate such behavior in practice.

Although, these questions have not yet received much attention from an empirical perspective, three recent papers provide results that are closely related to the issues examined here. The first is the recent investigation of the re-entry hypothesis as a potential explanation for the January effect by Cuny, Fedenia and Haugen (1995). After examining year-end trading practices, Cuny, Fedenia and Haugen report that some managers of mutual funds and pension funds tend to mimic the S\&P 500 index towards the end of the year but switch to riskier strategies as the new year turns. Such evidence tends to support the hypothesis that some risk manipulation occurs, at least around year-end. The other two papers, by Brown, Harlow and Starks (1996), and Chevalier and Ellison (1995) examine differences in risk behavior as resulting from a tournament with a prize being the inflow of new assets to

\footnotetext{
${ }^{2}$ Such behavior has long been conjectured in the literature. For an exposition in the context of the management of pension funds see Lakonishok, Shleifer and Vishny (1992).

${ }^{3}$ Dubins and Savage (1965) describe the "bold strategy" as one in which a casino player doubles his bet until he either achieves his goal or is wiped out, and show conditions under which it is optimal. By comparison, in describing the trading leading to the recent collapse of Barings, the New York Times reported: "Barings executives said the trades appeared to have been a classic attempt by a trader to cover mounting losses by making bigger and bigger bets." (February 27, 1995, page D5, column 1.)
} 
the mutual fund. (In this sense, these papers collapse the two layers of agency problems into one and do not explicitly deal with compensation incentives.) Both base their hypotheses on the empirical finding that inflows are more sensitive to recent good performance than outflows are to recent bad performance (see e.g. Sirri and Tufano, 1992). While Brown, Harlow and Starks suggest that funds with relatively bad performance may be induced to increase risk relative to other funds at year-end, Chevalier and Ellison suggest a more complex nonlinear relationship is likely to obtain which might encourage some top performing funds to attempt an increased risk year-end strategy.

The evidence presented in this paper suggests that incentive compensation has substantial influence on risk-taking decisions throughout the year. Measuring risk in terms of deviations of individual fund performance from the median within an investment objective (a measure of great interest to an investor who is has already chosen that objective as an investment strategy), we can observe a strong seasonal component on average risk with risk reaching a peak in the first quarter of the year. However the relationship between withinyear performance, especially towards year-end, appears to have changed over time. On the downside, the evidence suggests excess risk taking by losing managers early in the sample but not in later years. On the upside, the evidence suggests reductions in risk taking by winning managers towards year-end in later years but not early in the sample. A likely explanation for these changes is the concurrent change in the structure of compensation in the industry, particularly the greater reliance on bonuses versus base salary. A reassuring implication is that risk monitoring in the industry appears, at the present at least, to be sufficient to deter common use of "bold strategy" behavior.

The paper is organized in five sections. Following the introduction, in section two, I briefly describe the nature of incentives faced by mutual funds and compensation practices in the industry. In section three, I describe the source of the potential for seasonal and past performance dependent risk variations and in section four I provide estimates of this variation based on growth and growth and income mutual funds. Section five concludes. 


\section{Incentives in the mutual fund industry}

The three basic factors entering a mutual fund manager's decision problem are: base compensation, incentive bonus, and separation risk. While the specific details of these factors vary from company to company and over time, it is useful to provide a broad overview of frequently encountered elements to assess potential sources of seasonal and performance driven risk-taking patterns.

The first, base compensation, is readily understood, and possibly the only factor known in advance by fund managers with no ambiguity. Raises in base salary may follow after demonstrated superior performance in previous years but this is not necessarily the case since another form of raising a manager's expected annual compensation is to offer more lucrative incentive clauses rewarding future superior performance. Importantly, a significant trend towards lesser reliance on base salaries and greater reliance on incentive bonuses for compensation has been observed over the past decade following similar trends in trading houses with which mutual fund companies often compete for fund management talent.

The second factor, incentives, is designed to reward two important elements, the ability of the manager to achieve a high return for the fund relative to its characteristics and the ability of the manager to attract new assets to the fund. In principle, the latter is more important to the mutual fund company since fees generated from the volume of assets are the revenue base for the mutual fund operation. But since past performance of mutual funds is perhaps the primary determinant of asset growth and new asset inflows are also greatly influenced by activities of the company independent of the performance of the mutual fund manager (e.g. advertising and promotional activities) and other factors (e.g. banking deposit rates) in practice incentive contracts are specified primarily in terms of the manager's success in securing above-average returns relative to one or multiple benchmarks.

The maximum size of a bonus is typically set as a multiple of base salary. Superior performance exceeding some upper limit may therefore be of little benefit to a manager. Indeed, an important difference between the compensation in mutual fund companies and 
some of the other players in the trading business, e.g. hedge fund operations, is the presence of an upper limit on compensation incentives. This limit, in turn becomes the most obvious source of bonus "lock-in" behavior by managers with superior performance in the mutual fund industry.

A critical element of the structure of incentives for creating the potential for systematic changes in risk is the evaluation period. Most often evaluation is based on calendar year performance, either exclusively or in large part. As a result, within-year variations in risktaking may occur. An important alternative which mitigates these incentives however, is for the evaluation period to be in part the current calendar year, and in part the cumulative performance over a longer rolling (fixed length) horizon, such as 3 years. In some cases, the evaluation period is not the calendar year but a rolling four quarter horizon which would also effectively mitigate incentives for variations in risk taking. To the extent that the predominant evaluation horizon is the calendar year, however, any resulting seasonal and performance related risk patterns should be detectable in the data for the industry.

The comparison basis for the evaluation is typically the relative performance of the fund in its category as that is defined by the investment objective of the fund and perhaps by its asset size. A frequently mentioned resource for the definition of categories and performance rankings is the classification by Lipper Analytical or Wiesenberger Investment or other companies which provide similar classifications.

An additional complication is that some funds may be managed by multiple managers and, in turn, some managers may jointly manage more than one fund. In such situations the incentive part of a manager's compensation is typically computed separately for the different funds based on an agreed-upon allocation of the manager's services to the different funds. The most common arrangement, however, is for a manager to be responsible primarily for a single fund.

The final factor in the fund manager's decision is the risk of separation. Separations are partly based on performance considerations and partly on other factors. A manager who is consistently underperforming for a period of time risks a forced separation. But 
this separation may occur at any time within a year with no expected seasonal variation. Another factor for separation decisions is disagreement over the management of a fund which could stem from deviations by the manager from the fund's stated objectives. Indeed, excess risk taking or diminished risk taking would fall in this category potentially leading to separation. In practice, however, it appears that while mutual fund companies attempt to be vigilant against excess risk taking - especially by managers who have not been performing very well-diminished risk taking appears to be of lesser concern. Such asymmetries in treating deviations from the risk which would be consistent with a mutual fund's objectives may nonetheless contribute to systematic variations in risk taking.

For the mutual fund company the goals and incentives are clearly different from those faced by individual fund managers but also depend on the performance of the fund. An important factor for the profitability of a mutual fund is its size and the ability of the company to attract new assets into the fund. But, as an empirical matter, the single most important determinant of asset inflow is the recent past performance of the fund relative to other similar funds, and more broadly, other investments. (Indeed, it is presumably for this reason that the incentive clauses of fund manager contracts are primarily specified in terms of the fund's performance.) As a result, depending on the shape of the relationship between performance and asset inflow, fund companies may find it desirable to attempt to manipulate fund riskiness and thus attempt to influence a fund's relative performance over a fixed horizon.

However, it is not clear that there is a reason for these incentives to have a seasonal pattern. One potential source of such a seasonal pattern might have been the presence of a seasonal in aggregate net mutual fund inflows driven by seasonal substitution between mutual fund deposits and bank deposits. But in analysis of aggregate flows between M2 assets and mutual funds along the lines of in Orphanides, Reid and Small (1994), no such seasonal was uncovered. Another potential source of a seasonal could be due to investors evaluating alternative funds based only on calendar year performance. This, however, is unlikely since investors can costlessly evaluate a fund's past performance at any time of 
year with up to date performance horizons. (For instance, the Wall Street Journal lists on a weekly basis the average returns of mutual funds for 4 week, 12 month, three year and five year rolling horizons. In addition it lists quantile performance rankings relative to funds with the same investment objectives). Information was not as widely available on such a timely basis in the past, however, so it is possible that in earlier years calendar year performance (which has always been more widely available) might have created seasonal risk variation incentives for mutual fund companies.

Even if mutual fund companies had incentives for seasonal variations in risk, implementation of these objectives might have been be problematic. In the end, the actual implementation of a fund's strategy is, undertaken by the fund manager. As a result, the success of a mutual fund company in manipulating the risk of a particular fund may be limited to instances when its desires are compatible with the manager's optimal choices. To that end, any seasonal risk variation observed in practice is likely to be more representative of the manager's incentives - given her incentive compensation contract-rather than the mutual fund company's. It would, of course, broadly reflect the incentives of a mutual fund company, as those incentives are reflected in the design of the incentive compensation contract faced by the manager.

\section{Incentive contracts and risk taking behavior}

Consider a family of competing mutual funds indexed by $i \in\{1 \ldots N\}$ which share broadly similar characteristics from the perspective of potential investors so that their performance be evaluated relative to each other.

The mutual fund manager operating fund $i$ is given the primary objective to maximize the expected return of the fund period by period subject to maintaining the risk of the portfolio close to that of the benchmark consistent with the mutual fund's objectives. Let $R_{i t}$ be the fund's return during period $t$ and $R_{B t}$ be the return to the benchmark portfolio

(e.g. the mean or median return for funds in the family). Operationally, I will assume 
that the manager is instructed to keep the risk of deviations of the fund's return from its benchmark, $R_{i t}-R_{B t}$, close to a target level $X_{i}^{*} .{ }^{4}$ The actual risk of fund $i$ (relative to the benchmark) for period $t, X_{i t}$, though related to $X_{i}^{*}$ is for the most part under the manager's control. For simplicity, suppose that the manager faces an incentive contract with two major elements:

(1) Compensation: Conditional on not being dismissed, the manager is rewarded at the end of the year based on the cumulative performance of the fund during the calendar year, relative to the benchmark, $R_{B}$.

(2) Separation: To the extent $X_{i t}$ substantially deviates from $X_{i}^{*}$ during period $t$, and this is observed the manager may be dismissed. Further, if the manager is consistently underperforming, she may be dismissed.

Here, the second element captures the potential disciplinary actions that a manager may face if her actions deviate from the fund's objectives and also the concern that continuing underperformance may lead to dismissal; The first captures the nature of incentives. To make this element more precise some additional notation is required.

Let each year consist of $T$ periods, $\tau(t) \in\{1, \ldots, T\}$ be a seasonal index function denoting the within-year period (season) corresponding to $t$, and $y(t)$ a step function denoting the time corresponding to the last period of the year in which $t$ belongs. Thus, $y(t)=t$ whenever $t$ is the last period of the year and $y(t)=t+k$ if $t$ is $k$ periods away from the end of the year.

Suppose $Z_{i, t+1}^{j}$ is an index denoting the relative cumulative performance of fund $i$ for the $j$ periods ending at the end of period $t$. Then, the first element of the manager's contract effectively stipulates that her compensation for the year containing period $t$ will be a function of $Z_{i, y(t)+1}^{T}$, the end-of-year index for the cumulative performance over the previous $T$ periods, i.e. the calendar year. Importantly, the compensation will be a function of the same performance index for all $T$ periods within a calendar year. Consequently, a manager's optimal choice of risk in every period of a given year will be a function of

\footnotetext{
${ }^{4}$ In principle the target risk levels ought to be similar for all funds in the family but need not be identical.
} 
her expectations regarding her calendar year relative performance. The information upon which a manager can base her decision, however, is changing within the year, as her previous performance within the year is a partial determining factor of her calendar year performance. This suggests that $X_{i t}$, in addition to being a function of $X_{i}^{*}$, should be a function of the season $\tau$ corresponding to time $t$ and the information regarding the relative performance of the fund in earlier seasons during the same year.

In addition to these season-specific performance driven effects on risk taking, past performance may affect $X_{i t}$ independent of season. The reason is that fund managers continuously face the possibility of dismissal and the probability of separation increases in the event of repeated underperformance. If a manager's optimal risk choices are affected by her assessment of the risk of losing her job in the current or later periods, $X_{i t}$ would likely depend on past performance regardless of season. ${ }^{5}$

So, to the extent incentive contracts influence risk decisions, $X_{i t}$ should be a function of both non-season-specific and season-specific past performance. Without imposing further structure on the manager's decision problem, little can be said regarding the specification of such a function. As an empirical matter, however, $X_{i t}$ can be modeled as a time invariant function of the target risk level, $X_{i}^{*}$, the season, $\tau(t)$, and the summary statistics of past performance such as the cumulative performance until the end of the previous period, $Z_{i t-1}^{\tau(t)-1}$. Let $D_{t}^{j}$ be season specific dummy variables such that $D_{t}^{j}=1$ if $\tau(t)=j$ and 0 otherwise. For concreteness, I assume that this function can be linearly separated into the season specific and remaining effects as follows:

$$
X_{i t}=X\left(X_{i}^{*}, Z_{i t}^{1}, \ldots\right)+\sum_{\tau=2}^{T} D_{t}^{\tau} f^{\tau}\left(Z_{i t}^{\tau-1}\right)
$$

The specification of risk decisions in (1) leads to a very convenient interpretation. The first period risk decision, $X($.$) can be interpreted as a baseline X_{i t}$ choice embodying the

\footnotetext{
${ }^{5}$ Since these non-season specific effects, however, may be driven also by factors other than compensation incentives, their presence would not be as informative for our purposes as the season specific effects.
} 
non-incentive driven determinants of risk choices such as the fund specific target $X_{i}^{*}{ }^{6}$ The season-specific functions, $f^{\tau}($.$) , then, provide a measure of deviations in risk choices from$ that baseline, likely due to compensation incentive effects.

As a reminder, however, it should be noted that the risk choices to be made in equilibrium, as represented by the specification in (1) are conditioned on the two key elements faced by the manager, that is the compensation schedule faced, and the risk of separation. Consequently, changes in the structure of compensation (such as the increased reliance on bonuses over the past several years) are likely to lead to changes in the resulting equilibrium risk decisions.

\section{Empirical implementation}

\subsection{Data}

Our sample consists of two groups of the most popular equity mutual funds, growth funds, and growth and income funds. The raw data, obtained from Morningstar, are the unbalanced panels of quarterly returns for the two families from 1976 to 1993 . The population consists of all funds in these two categories that were in existence in 1994. Unfortunately, data for funds which existed early on in the sample but did not operate in 1994 (for example due to mergers) were not available for analysis. As a result, our sample suffers from the survivorship bias which has affected some work relating to the persistence of mutual fund performance. ${ }^{7}$ Since I am not concerned with comparisons of performance of different funds over long horizons but rather with their within-year risk differences the survivorship issue is unlikely to have a significant impact on the empirical results. ${ }^{8}$

After eliminating funds with fewer than three years of data in order to allow for the

\footnotetext{
${ }^{6}$ As noted earlier, this also includes in principle, non-seasonal compensation incentive effects, but separation of the two is not possible without additional information.

${ }^{7}$ See Brown, et al. (1992), Elton, Gruber and Blake (1995) and Goetzmann and Brown (1993).

${ }^{8} \mathrm{An}$ exception is with regard to a trend in the overall variance of returns. Since funds in the lower tail of the cross sectional distribution of returns are less likely to survive, remaining funds will tend to exhibit lower dispersion in earlier years of the sample. Consequently, these data cannot be used to make inferences regarding possible trends in the cross-sectional dispersion of returns.
} 
creation of lags, our sample consisted of 299 growth funds and 185 growth and income funds. For each quarter and each family, I computed the median return and constructed the absolute deviation of every fund's return from its family median for the quarter, $D V_{i t}$. This was used as a means of estimating an ex-post index of the quarterly risk choice by the mutual fund managers.

Finally, for each quarter for which it was possible, I computed the one-, two- and threequarter cumulative returns for each fund as well as the median returns for each family. I then constructed the differences between the cumulative fund returns and the corresponding cumulative median and divided all the three variables by the standard deviation of the onequarter difference computed by pooling all funds (within each family) in all quarters, and lagged the three variables by 1 quarter. The three resulting variables define the cumulative past performance variables $Z^{1}, Z^{2}$ and $Z^{3}$, standardized by the one-quarter difference standard deviation. Thus, a fund which has underperformed its benchmark (i.e. the median for the family) during quarter $t-1$ by one standard deviation of the one-quarter difference will have the index $Z_{t}^{1}$ equal to -1 . Similarly, a fund which has underperformed its benchmark for the two quarters, $t-1$ and $t-2$ by one standard deviation of the one-quarter differ-

ence in each quarter, will have the index $Z_{t}^{2}$ equal to -1 . Table 1 provides some summary statistics of the resulting variables for the two families of funds. Note that since the onequarter difference is used to normalize all three measures of cumulative past performance, the standard deviations of $Z^{2}$ and $Z^{3}$ are smaller than one. Also, from the $5 \%$ and $95 \%$ percentile values, it should be clear that the relevant region for values of the performance variables falls within the $(-2,+2)$ region which is convenient for a visual examination of the estimation results later on.

\subsection{Specification}

Next, we use least squares to examine the presence of seasonal/past performance related patterns in risk. To that end, we estimate panel regressions based on the specification of 
equation (1):

$$
D V_{i t}=X\left(X_{i}^{*}, Z_{i t}^{1}, Z_{i t}^{2}, Z_{i t}^{3}\right)+\sum_{\tau=2}^{T} D_{t}^{\tau} f^{\tau}\left(Z_{i t}^{\tau-1}\right)+b_{d 1} D V_{i t-1}+b_{d 2} D V_{i t-2}+b_{d 3} D V_{i t-3}
$$

allowing three lags of the dependent variables in the specification to capture potential inertia in quarter to quarter risk index movements. We specify a linear form for the baseline choice of $X$ to capture possible non-season specific effects of past performance on risk, and in addition, allow fund specific intercepts to capture the possible idiosyncratic variation in $X_{i}^{*}$ :

$$
X(.)=b_{i}+b_{11} Z_{i t}^{1}+b_{12} Z_{i t}^{2}+b_{13} Z_{i t}^{3}
$$

For estimating seasonal performance effects (for $\tau>1$ ) we allow for a quadratic function of past performance in order to permit the data to uncover in a parsimonious fashion simple non-linearities in the relationship between past performance and risk:

$$
f^{\tau}\left(Z_{t}^{\tau-1}\right)=b_{\tau 0}+b_{\tau 1} Z_{i t}^{\tau-1}+b_{\tau 2}\left(Z_{i t}^{\tau-1}\right)^{2}
$$

\subsection{Estimation Results}

Tables 2 and 3 present the estimation results for the two categories of funds respectively. Regression \#1 only includes a constant and three seasonal dummy variables and thus provides estimates of the average variation in risk taking behavior that occurs in any given year. The coefficient $b_{00}$ provides the mean risk for the first quarter while the coefficients $b_{20}, b_{30}$ and $b_{40}$ the additional average risk for quarters two, three and four. As can be seen, an interesting seasonal pattern emerges. On average, risk is lowest during the second quarter of the year, rises in quarters three and four and reaches a peak in the first quarter. Comparison of the two categories of funds indicates that the same pattern obtains in both. To be noted, the finding of the seasonal peak in risk occuring in quarter one, is consistent with the re-entry hypothesis of the January effect.

Regression \#2 shows the full sample estimates of the within-year past performance effect 
on risk. Overall, the implied risk choices in quarter two are smaller than the first quarter risk benchmark. The strong negative coefficients on the quadratic terms for quarters 2 and 3 , however, indicate that funds with extreme performances (both positive and negative) tend to reduce risk by more than funds of average performance. The curvature not withstanding, only a slight positive overall relation between risk and past performance appears in quarters two and three. (None appears for growth and income funds in quarter 2). For quarter four, the estimates indicate a slight overall negative relation between risk and past performance.

Because of the gradual changes in the structure of compensation incentives which has occurred during the sample, I checked for any potential changes in these relationships through time, dividing the data into those corresponding to observations early in the sample and those corresponding to observations late in the sample. The results from these additional regressions (not shown) suggested the presence of significance shifts in the relationship especially for quarter four.

This finding suggested that the shift in managerial compensation towards contracts emphasizing relative performance bonus versus base salary likely did have an effect in changing through time the risk choices taken by managers within a year in relation to their past performance. To assess the magnitude of these changes in a parsimonious fashion I introduced time interaction variables in the regression corresponding to the variables shown in the tables. (That is, I added the variables $Y_{t}, Y_{t} Z_{i t}^{\tau-1}$ and $Y_{t}\left(Z_{i t}^{\tau-1}\right)^{2}$ in the specification of $f^{\tau}\left(Z_{i t}^{\tau-1}\right)$ where $Y_{t}$ is an annual trend variable.) Effectively this allowed for smooth changes in the shape of the risk-performance relationship through time and provided year specific patterns which could indicate the differences between early and late years in the sample.

The estimation results are shown as regression \#3 in the tables 2 and 3 . For each regression, I computed the implied season specific risk-performance relationships, $f^{\tau}($.$) , for$ two years in the sample, 1980 and 1990. The results are shown in the last two columns of the tables. As can be seen, from the tables, the difference in the fourth quarter estimates for the two years is quite substantial. While in 1980, the risk choices of extreme performers in the fourth quarter were higher than for the median performers, by 1990 the reverse tendency 
appears.

The estimated relationships are shown graphically in Figures 1 through 4 . Figures 1 and 2 correspond to the estimates for growth funds (for years 1980 and 1990 respectively) while figures 3 and 4 show the parallel estimated relationships for growth and income funds. In each figure, separate panels plot the estimated functions $f^{\tau}\left(Z_{t}^{\tau-1}\right)$, as shown in Tables 2 and 3, which capture the relationship between each of the quarters two, three and four, and the corresponding within-year past performance up to the end of the previous quarter. In all cases, the difference in the risk implied for the quarter from the baseline first quarter risk estimate is shown.

Comparing Figures 1 and 2 for growth funds, indicates that while early in the sample managers who had outperformed their benchmark tended to increase risk, later in the sample better than average performance by the end of quarters 3 and 4 tends to imply reduced risk positions. A likely explanation for the difference is the increased importance of the incentive bonus part of total compensation in recent years. With a greater fraction of compensation being determined by relative performances managers may have increasingly greater incentives to lock in their gains towards the end of the year.

Regarding managers who have performed poorly, the evidence suggests that while early in the sample underperformers may have been following a "bold strategy" towards the end of the year, no discernible increase in risk towards the end of the year appears later in the sample. A likely explanation is that mutual fund companies may monitor the risk taking behavior by their managers much more closely now than in the past and exhibit less tolerance towards excess risk. With that avenue being closed, underperforming managers may attempt to reduce their probability of layoff due to continuing underperformance by targeting a performance perhaps closer to that of their benchmark towards the end of year. 


\section{Conclusion}

In this paper I examine the role of compensation contracts in determining risk taking decisions in the financial industry. Concentrating on mutual fund managers of growth and growth and income mutual funds, I exploit the within-year cross sectional variation in the performance of the funds in each group, to identify systematic patterns in season specific, past performance related risk.

The evidence suggests that the structure of compensation incentives may have substantial influence on risk decisions. A strong seasonal component on average risk is present with risk reaching a peak in the first quarter of the year. However the relationship between within-year performance and risk, especially towards year-end, appears to have changed significantly over time.

For winning managers, the evidence suggests reductions in risk taking towards year-end in later years but not early in the sample. This evidence is consistent with the higher stakes involved in the incentive compensation faced by mutual fund managers later in the sample which tends to encourage bonus "lock-in" behavior.

For badly performing managers, while some systematic excess risk taking appears early in the sample, such behavior is not apparent in later years. This reassuring result suggests improvements in risk control management by mutual fund companies during the sample, which may have occured either because the industry has matured or in conjunction with the shift towards greater emphasis on performance based compensation arrangements.

Overall, the presence of past performance related variations in risk suggests that the agency problem in the industry with regard to risk taking is not a mere theoretical possibility but is of practical significance. The results presented indicate that the potential for abuse is indeed present, and raise the importance of continuous vigilance against excessive risk taking and the importance of effective risk assessment and control in the industry. It is reassuring that the evidence presented suggests that at least in the later years in the sample, the risks exhibited by the mutual funds examined is consistent, on average, with 
adequate risk control by the mutual fund companies.

Unfortunately, in the absence of more detailed data regarding the compensation arrangements followed by different companies, a more detailed assessment of compensation incentives and risk taking is not feasible. If such data were available, direct comparisons of the resulting differences in risk taking behavior would have permitted an evaluation of the relative merits and drawbacks of different compensation arrangements with regard to risk.

Finally, these results draw attention to the importance of effective risk management and control in trading activities not just for mutual funds but over a wider spectrum in money management and securities trading. Information helpful in examining compensation arrangements and risk management practices by companies involved in these activities would therefore appear to be of great value. 


\section{References}

Brown, Keith C., W. V. Harlow and Laura T. Starks, "Of Tournaments and Temptations: An Analysis of Managerial Incentives in the Mutual Fund Industry," Journal of Finance, 51(1), 85-110, March 1996.

Brown, Stephen, William Goetzmann, Roger G. Ibbotson, and Stephen A. Ross, "Survivorship Bias in Performance Studies," Review of Financial Studies, 5(4), 553-580, 1992

Chevalier, Judith, and Glenn Ellison, "Risk Taking by Mutual Funds as a Response to Incentives," NBER Working Paper Number 5234, August 1995.

Cuny, Charles, Mark Fedenia and Robert Haugen, "Professional Investor Re-entry and the January Effect," mimeo, June 1995.

Dubins, Lester E., and Leonard J. Savage, Inequalities for Stochastic Processes: How to Gamble if You Must, Dover, 1976.

Elton, Edwin J., Martin J. Gruber, and Christopher R. Blake, "Survivorship Bias and Mutual Fund Performance," New York University Salomon Center Working Paper, S95-14, March 1995.

Goetzmann, William N., and Stephen Brown, "Attrition and Mutual Fund Performance: Evidence from a Survivorship-Bias Free Database," mimeo, 1993.

Grinblatt, Mark, and Sheridan Titman, "Adverse Risk Incentives and the Design of PerformanceBase Contracts," Management Science, 35(7), 807-822, July 1989.

Hirshleifer, David, and Yoon Suh, "Risk, Managerial Effort, and Project Choice," Journal of Financial Intermediation, 2, 308-345, 1992.

Holmstrom, Bengt, and Paul Milgrom, "Aggregation and Linearity in the Provision of Intertemporal Incentives," Econometrica 55(2), 303-328, March 1987

Modigliani, F. and G. A. Pogue, "Alternative Investment Performance Fee Arrangements and Implications for SEC Regulatory Policy," Bell Journal of Economics and Management Science, 6, 127-160, 1975.

Orphanides, Athanasios, Brian Reid, and David H. Small, "The Empirical Properties of a Monetary Aggregate That Adds Bond and Stock Mutual Funds to M2," Federal Reserve Bank of St Louis Review, 76(6), 31-51, November/December 1994.

Sirri, E. and P. Tufano, "The Demand For Mutual Fund Services by Individual Investors," Harvard Business School Working Paper, 1992.

Starks, Laura, "Performance Incentive Fees: An Agency Theoretic Approach" Journal of Financial and Quantitative Analysis, 22, p 17-32, March 1987.

Stoughton, Neal M., "Moral Hazard and the Portfolio Management Problem," Journal of Finance, 48(5), p. 2009-2028, December 1993 
Table 1

Summary statistics

\begin{tabular}{lrrrr}
\hline Variable & Mean & Std Dev & $5 \%$ & $95 \%$ \\
\hline \hline \multicolumn{5}{c}{ Growth funds } \\
$D V$ & 0.901 & 0.838 & 0.056 & 2.491 \\
$Z 1$ & 0.032 & 1.000 & -1.498 & 1.686 \\
$Z 2$ & 0.019 & 0.726 & -1.123 & 1.235 \\
$Z 3$ & 0.005 & 0.593 & -0.945 & 0.984 \\
\hline \multicolumn{5}{c}{ Growth and income funds } \\
$D V$ & 0.688 & 0.687 & 0.038 & 2.010 \\
$Z 1$ & -0.011 & 1.000 & -1.594 & 1.482 \\
$Z 2$ & -0.017 & 0.734 & -1.203 & 1.080 \\
$Z 3$ & -0.021 & 0.612 & -1.002 & 0.905 \\
\hline
\end{tabular}

Notes: The underlying data is the deviation of a fund's quarterly return from the median return for funds with the same objective. It is measured in percent on a monthly basis. $D V$ is the absolute value of this deviation. $Z 1, Z 2$, and $Z 3$ are the one, two, and three quarter cumulative deviations from the median divided by the standard deviation of the one quarter deviation. 
Table 2

Estimation of season specific deviations from baseline risk

Growth funds

\begin{tabular}{lccccc}
\hline \multicolumn{2}{c}{ Regression } & $\# 1$ & $\# 2$ & $\begin{array}{c}\# 3 \\
(1980)\end{array}$ & $\begin{array}{c}\# 3 \\
(1990)\end{array}$ \\
\hline \hline & $b_{00}$ & 1.000 & & & \\
& & $(0.015)$ & & & \\
2nd Quarter & $b_{20}$ & -0.206 & -0.154 & -0.084 & -0.188 \\
$f^{2}\left(Z^{1}\right)$ & & $(0.022)$ & $(0.022)$ & $(0.039)$ & $(0.026)$ \\
& $b_{21}$ & & 0.051 & 0.028 & 0.061 \\
& & & $(0.018)$ & $(0.028)$ & $(0.020)$ \\
& $b_{22}$ & & -0.058 & -0.041 & -0.062 \\
& & & $(0.008)$ & $(0.016)$ & $(0.008)$ \\
3rd Quarter & $b_{30}$ & -0.129 & -0.097 & -0.083 & -0.102 \\
$f^{3}\left(Z^{2}\right)$ & & $(0.022)$ & $(0.022)$ & $(0.039)$ & $(0.026)$ \\
& $b_{31}$ & & 0.056 & 0.085 & 0.040 \\
& & & $(0.025)$ & $(0.037)$ & $(0.028)$ \\
& $b_{32}$ & & -0.046 & -0.009 & -0.064 \\
& & & $(0.016)$ & $(0.027)$ & $(0.018)$ \\
4th Quarter & $b_{40}$ & -0.096 & -0.103 & -0.091 & -0.105 \\
$f^{4}\left(Z^{3}\right)$ & & $(0.021)$ & $(0.021)$ & $(0.038)$ & $(0.025)$ \\
& $b_{41}$ & & -0.033 & -0.018 & -0.070 \\
& & & $(0.029)$ & $(0.041)$ & $(0.033)$ \\
& $b_{42}$ & & -0.011 & 0.161 & -0.072 \\
& & & $(0.021)$ & $(0.033)$ & $(0.024)$ \\
\hline
\end{tabular}

Notes: The equation is estimated with 11971 quarterly observations from 1976-1993 on an unbalanced panel of 299 growth mutual funds. The dependent variable is $D V$, the deviation of a fund's return from the median return. $Z_{t}^{\tau-1}$ is the cumulative performance index over $\tau-1$ quarters ending at quarter $t-1$. In $\# 1, f^{\tau}()=.b_{\tau 0}$. In $\# 2, f^{\tau}()=$. $b_{\tau 0}+b_{\tau 1} Z^{\tau-1}+b_{\tau 2}\left(Z^{\tau-1}\right)^{2}$. Fund specific constants, year specific constants, three lags of the dependent variable and $Z^{1}, Z^{2}, Z^{3}$ are also included in the regression but not shown here. In \#3, interaction terms with time are added to the specification in \#2. The estimates shown correspond to the estimated functions, $f^{\tau}($.$) , in 1980$ and 1990. Standard errors are in parentheses. 
Table 3

Estimation of season specific deviations from baseline risk

Growth and income funds

\begin{tabular}{|c|c|c|c|c|c|}
\hline \multicolumn{2}{|c|}{ Regression } & $\# 1$ & $\# 2$ & $\begin{array}{c}\# 3 \\
(1980)\end{array}$ & $\begin{array}{r}\# 3 \\
(1990)\end{array}$ \\
\hline \multirow{4}{*}{$\begin{array}{l}\text { 2nd Quarter } \\
f^{2}\left(Z^{1}\right)\end{array}$} & $b_{00}$ & $\begin{array}{c}0.756 \\
(0.016)\end{array}$ & & & \\
\hline & $b_{20}$ & $\begin{array}{l}-0.154 \\
(0.023)\end{array}$ & $\begin{array}{l}-0.126 \\
(0.022)\end{array}$ & $\begin{array}{c}-0.094 \\
(0.039)\end{array}$ & $\begin{array}{l}-0.142 \\
(0.026)\end{array}$ \\
\hline & $b_{21}$ & & $\begin{array}{l}-0.002 \\
(0.018)\end{array}$ & $\begin{array}{c}0.012 \\
(0.027)\end{array}$ & $\begin{array}{l}-0.005 \\
(0.021)\end{array}$ \\
\hline & $b_{22}$ & & $\begin{array}{l}-0.029 \\
(0.007)\end{array}$ & $\begin{array}{l}-0.022 \\
(0.012)\end{array}$ & $\begin{array}{l}-0.032 \\
(0.008)\end{array}$ \\
\hline \multirow[t]{3}{*}{$\begin{array}{l}\text { 3rd Quarter } \\
f^{3}\left(Z^{2}\right)\end{array}$} & $b_{30}$ & $\begin{array}{l}-0.103 \\
(0.023)\end{array}$ & $\begin{array}{l}-0.089 \\
(0.023)\end{array}$ & $\begin{array}{l}-0.111 \\
(0.039)\end{array}$ & $\begin{array}{l}-0.077 \\
(0.027)\end{array}$ \\
\hline & $b_{31}$ & & $\begin{array}{c}0.014 \\
(0.026)\end{array}$ & $\begin{array}{c}0.033 \\
(0.037)\end{array}$ & $\begin{array}{r}0.027 \\
(0.030)\end{array}$ \\
\hline & $b_{32}$ & & $\begin{array}{l}-0.020 \\
(0.015)\end{array}$ & $\begin{array}{l}-0.029 \\
(0.025)\end{array}$ & $\begin{array}{l}-0.017 \\
(0.018)\end{array}$ \\
\hline \multirow[t]{3}{*}{$\begin{array}{l}\text { 4th Quarter } \\
f^{4}\left(Z^{3}\right)\end{array}$} & $b_{40}$ & $\begin{array}{l}-0.040 \\
(0.022)\end{array}$ & $\begin{array}{l}-0.048 \\
(0.022)\end{array}$ & $\begin{array}{l}-0.078 \\
(0.038)\end{array}$ & $\begin{array}{l}-0.032 \\
(0.026)\end{array}$ \\
\hline & $b_{41}$ & & $\begin{array}{l}-0.045 \\
(0.029)\end{array}$ & $\begin{array}{l}-0.016 \\
(0.041)\end{array}$ & $\begin{array}{l}-0.068 \\
(0.034)\end{array}$ \\
\hline & $b_{42}$ & & $\begin{array}{l}-0.014 \\
(0.019)\end{array}$ & $\begin{array}{c}0.053 \\
(0.032)\end{array}$ & $\begin{array}{l}-0.015 \\
(0.025)\end{array}$ \\
\hline
\end{tabular}

Notes: The equation is estimated with 7433 quarterly observations from 1976-1993 on an unbalanced panel of 185 growth and income mutual funds. The dependent variable is $D V$, the deviation of a fund's return from the median return. $Z_{t}^{\tau-1}$ is the cumulative performance index over $\tau-1$ quarters ending at quarter $t-1$. In $\# 1, f^{\tau}()=.b_{\tau 0}$. In $\# 2$, $f^{\tau}()=.b_{\tau 0}+b_{\tau 1} Z^{\tau-1}+b_{\tau 2}\left(Z^{\tau-1}\right)^{2}$. Fund specific constants, year specific constants, three lags of the dependent variable and $Z^{1}, Z^{2}, Z^{3}$ are also included in the regression but not shown here. In \#3, interaction terms with time are added to the specification in \#2. The estimates shown correspond to the estimated functions, $f^{\tau}($.$) , in 1980$ and 1990. Standard errors are in parentheses. 
Figure 1

\section{Risk and within-year past performance}

Growth funds - estimated relation for 1980

\section{Second Quarter}

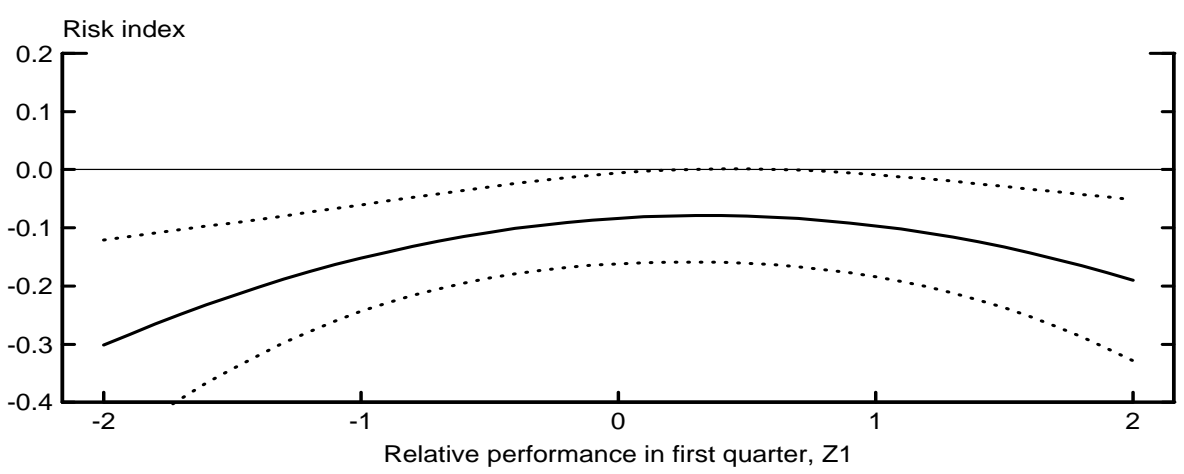

Third Quarter

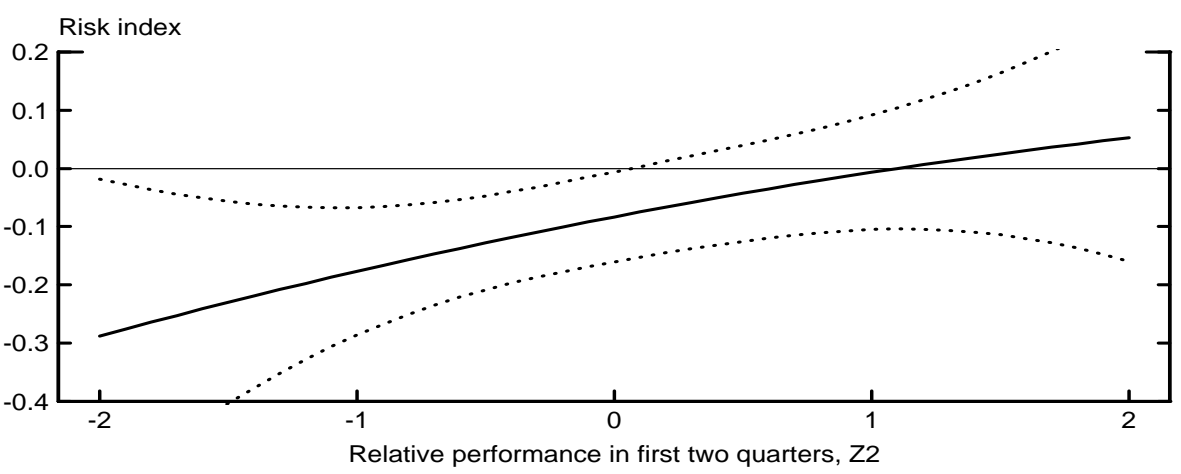

Fourth Quarter

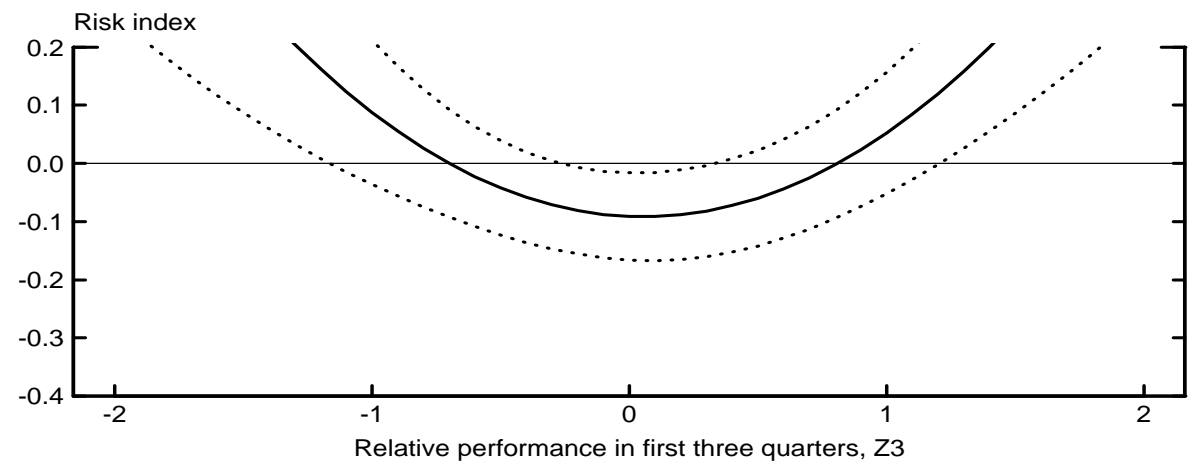

Notes: Each panel plots the estimated difference between the risk index for the quarter shown and the first quarter for a fund with the cumulative performance shown on the horizontal axis. The estimated index is the absolute deviation of a fund's return from the median return for the quarter. The dotted lines represent two standrad deviation bounds. 
Figure 2

\section{Risk and within-year past performance}

Growth funds-estimated relation for 1990

\section{Second Quarter}

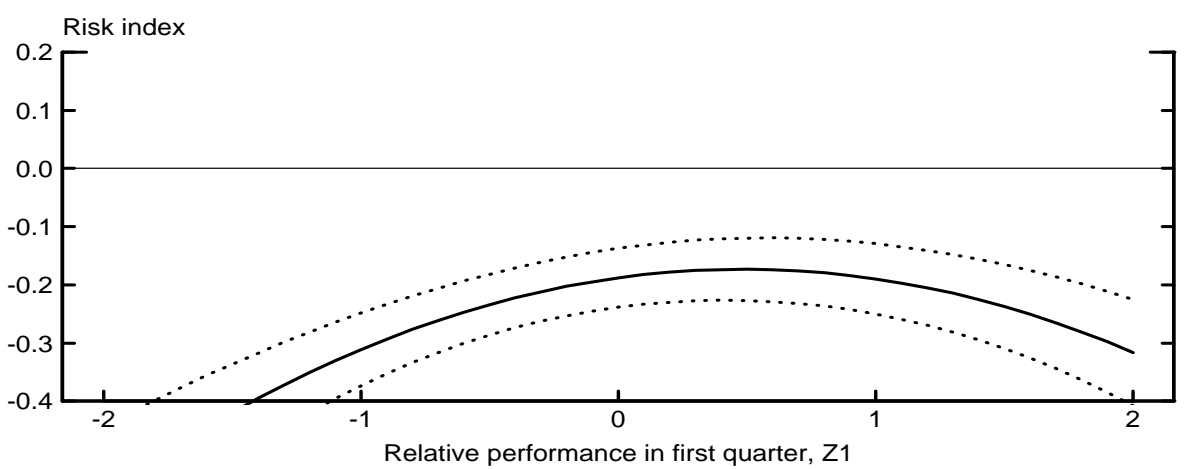

Third Quarter

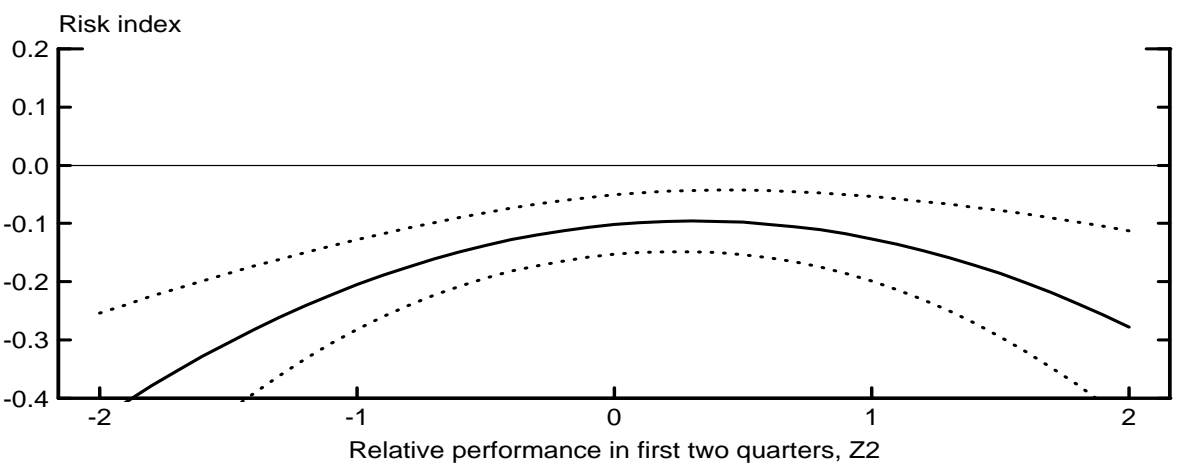

Fourth Quarter

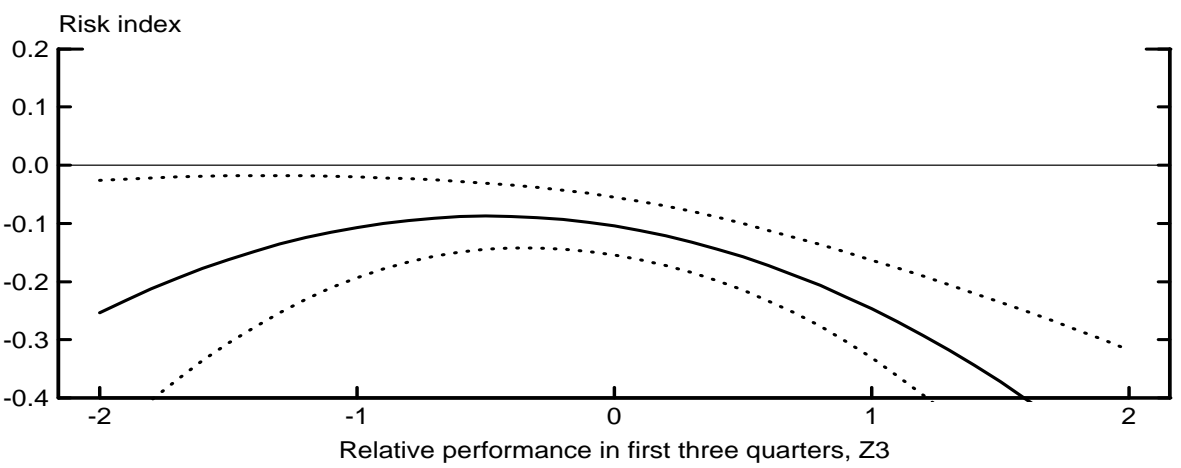

Notes: Each panel plots the estimated difference between the risk index for the quarter shown and the first quarter for a fund with the cumulative performance shown on the horizontal axis. The estimated index is the absolute deviation of a fund's return from the median return for the quarter. The dotted lines represent two standrad deviation bounds. 
Figure 3

\section{Risk and within-year past performance}

Growth and income funds - estimated relation for 1980

Second Quarter

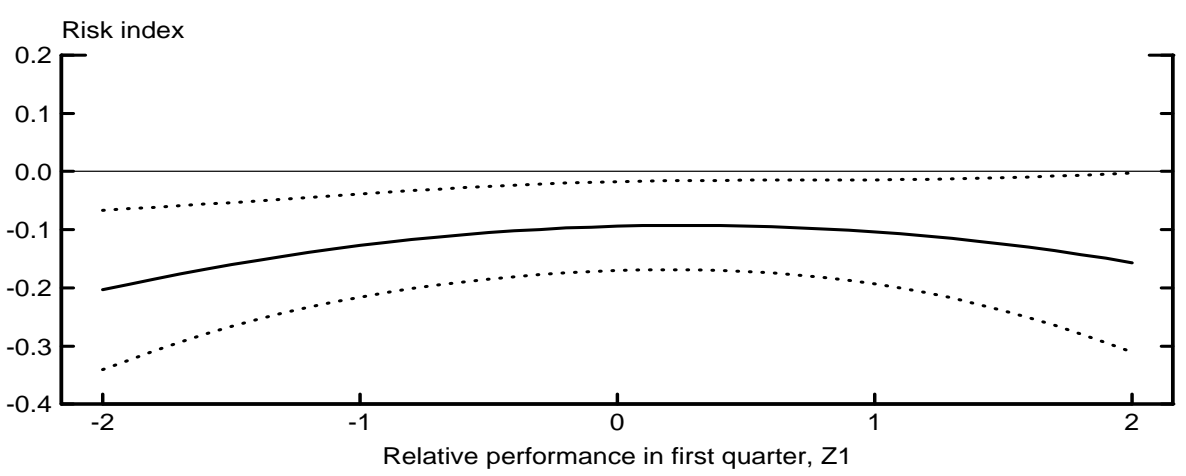

Third Quarter

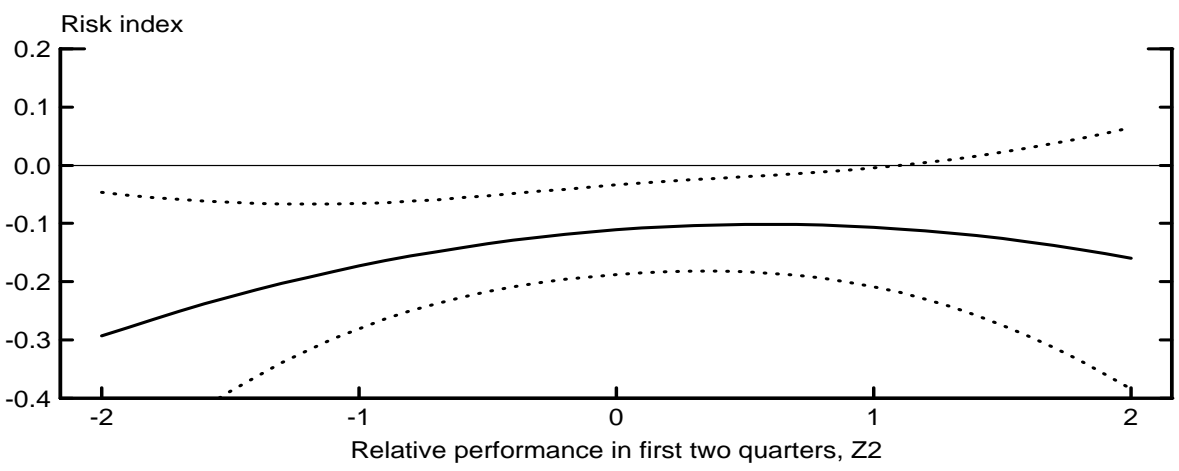

Fourth Quarter

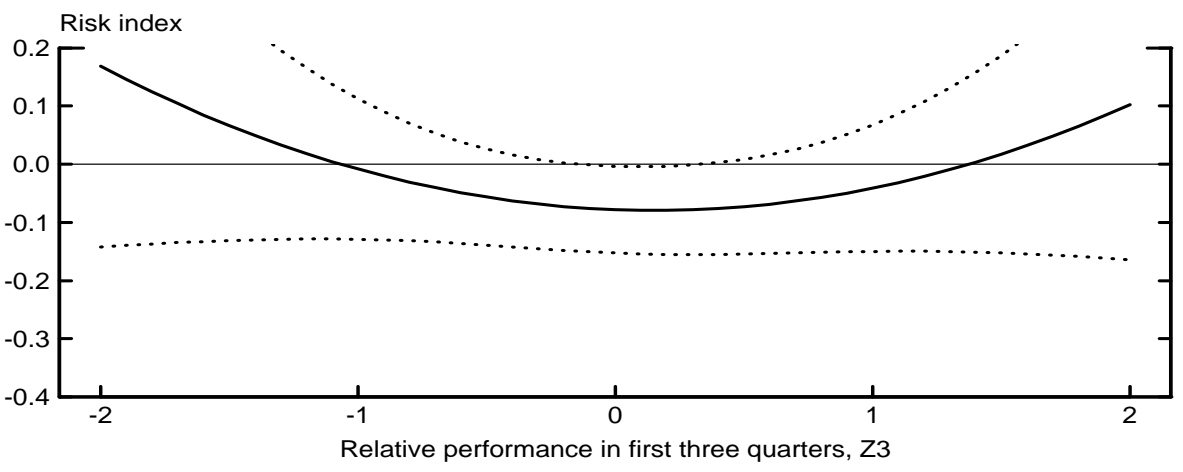

Notes: Each panel plots the estimated difference between the risk index for the quarter shown and the first quarter for a fund with the cumulative performance shown on the horizontal axis. The estimated index is the absolute deviation of a fund's return from the median return for the quarter. The dotted lines represent two standrad deviation bounds. 
Figure 4

\section{Risk and within-year past performance}

Growth and income funds - estimated relation for 1990

\section{Second Quarter}

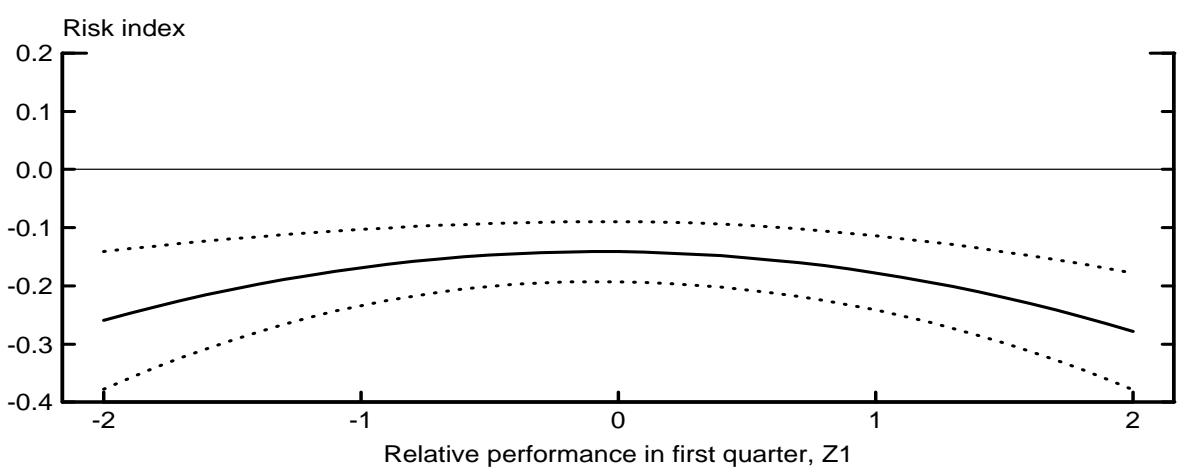

Third Quarter

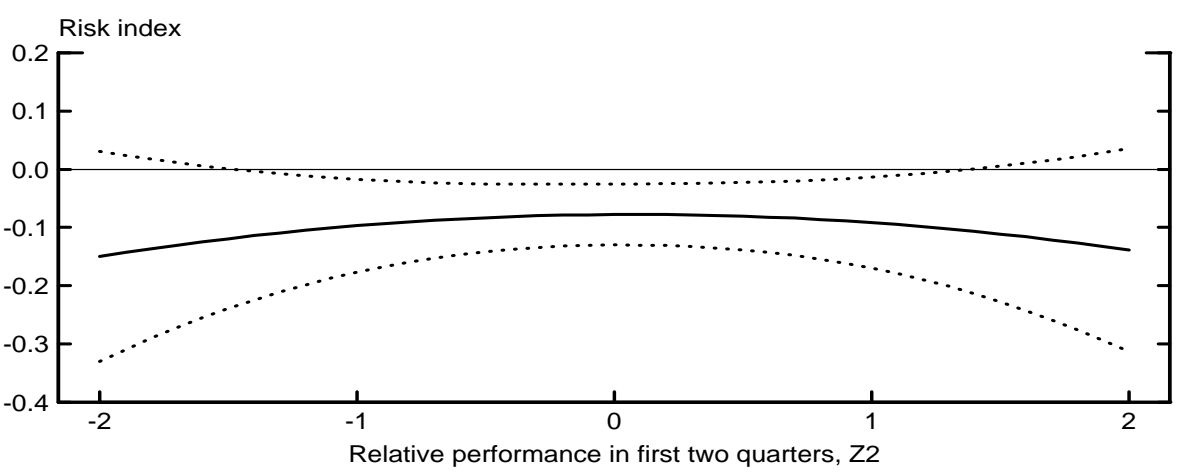

Fourth Quarter

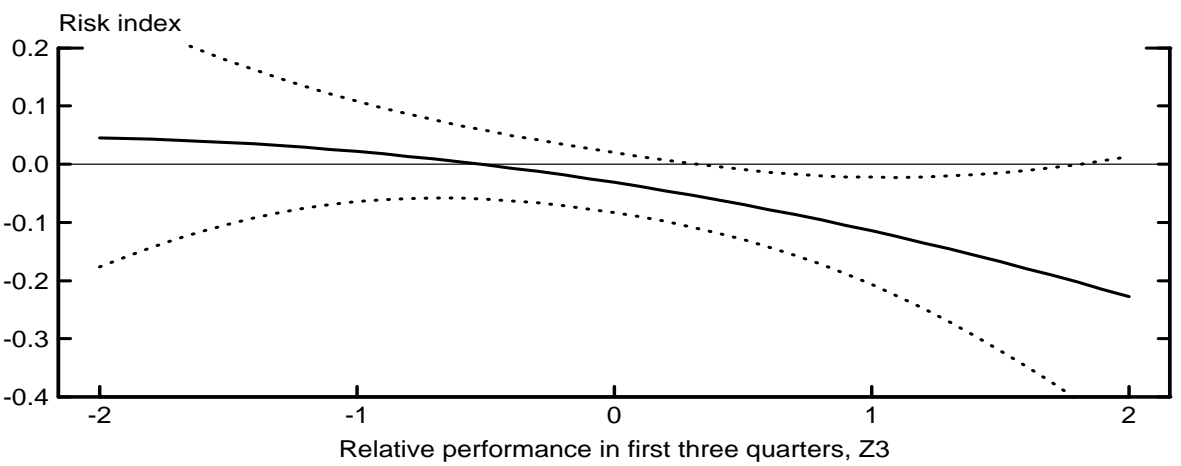

Notes: Each panel plots the estimated difference between the risk index for the quarter shown and the first quarter for a fund with the cumulative performance shown on the horizontal axis. The estimated index is the absolute deviation of a fund's return from the median return for the quarter. The dotted lines represent two standrad deviation bounds. 